\title{
Mortality Rate of People Exposed to Mustard Gas During Iran-Iraq War in Sardasht, Iran: A 32 Years Retrospective Cohort Study
}

Mohammad Hasan Rabiee

University of Tehran

Mostafa Ghanei ( $\nabla$ mghaneister@gmail.com )

Biotechnology Devrlopment Council https://orcid.org/0000-0001-9372-0928

Hossein Amini

Baqiyatallah University of Medical Sciences

Aliasghar Akhlaghi

Royan Institute

\section{Research}

Keywords: Mortality, Mustard gas, Sardasht, Iran

Posted Date: September 23rd, 2021

DOl: https://doi.org/10.21203/rs.3.rs-820705/v2

License: (c) (i) This work is licensed under a Creative Commons Attribution 4.0 International License. Read Full License 


\section{Abstract}

\section{Background:}

Mustard gas is one of the mostwidely used chemical weapons in the past century. Howeverlittle information existsconcerning long-term mortality due to MG exposure. In this study we investigated mortality rate among civilian people exposed to mustard gas during Iran-Iraq war in sardasht in Iran after 32 years.

\section{Methods:}

In this retrospective cohort study, data related to all people exposed to mustard gas in sardasht in 1987 were extracted from the Veterans and Martyr Affair Foundation of Iran up to March 20, 2019. Mortality rate, cumulative mortality and standardized mortality ratio with $95 \%$ confidence interval were calculated to explain mortality in the cohort and compare it with Iranian general population. Cox regression analysis used to indicatefactoraffected risk of death in the cohort.

\section{Results:}

Out of 1,203 exposed people at the beginning of the period, 148 people died by the end of the study, with an average age of 66.42 at the time of death. Total person-years of the people up to end of the study were 38198.63 and mortality rate was equal to 387 per 100,000 persons-years.Total number of observed deaths was less than expected death and theall-cause standardized mortality ratio (SMR) was 0.680.Cause-specific SMR showed that observed death due to respiratory diseases was higher than expected (SMR: 1.75). The results of univariate and multivariate cox regression analysis showed that increasing age and having severe latecomplication in lungincrease risk of death among people in the cohort.

\section{Conclusion:}

In general, this result indicated that acute exposure to mustard gas, even without wearing protective clothing and masks, will not increase all-cause mortality after 32 years if accompanied by special and ongoing carefor those exposed.

\section{Background:}

Mustard gas is one of the most well-known hazardous chemical agents which was synthesized first by Despretz in 1822 [1]. This fast-absorbing substance can enter the body through various routes including the respiratory tract, skin, anterior surface of the eye, and in some cases through the gastrointestinal tract which consequently can lead to recurrent complications in various organ and death in short term and long term [2-4]. 
The use of mustard gas as a chemical weapon in war has so far caused hundreds of thousands of people to be exposed to small or large amount of this agent in acute form. In other words, since the first use of mustard gas as a chemical weapon by the German army in 1917 in the war against Canadian and French troops, this agent has been repeatedly used in various wars against different countries such as Iran in the 8-years war between Iran and Iraq which has caused injury, complication and death to military and civilian people $[5,6]$.

Sardasht is one of the cities in Iran that during the Iran-Iraq war from 1981 to 1989 , civilians in this city were exposed to mustard gas. The city, located in northwestern Iran with latitude of 36.9 ' 4.48 " and a longitude of 10.46 ' $29.45 \otimes$, was bombed by the Iraqi government on July 28,1987 , during the Iran-Iraq war. The bombing dropped seven 250-kilogram mustard gas bombs, four of which exploded in a densely populated area downtown, affecting civilians [2].

Although so far, a limited number of studies have investigated the long-term mortality rate of exposed people to mustard gas in war, there was no information on long-term mortality in a civil population such as Sardasht [3, 7]. Indeed, all the people exposed to mustard gas in the city of Sardasht in 1987 during the Iran-Iraq war were civilians and have similar characteristics to the general population. In addition, these people have been exposed to this agent without wearing protective clothing and masks. On the other hand, so far and after 32 years of exposure of people to this agent in Sardasht, no study has measured the impact of exposure to mustard gas on mortality rate in these people. Therefore, in this study we investigate mortality rate among people exposed to mustard gas during Iran, Iraq war in sardasht in Iran after 32 years of exposure.

\section{Methods:}

\subsection{Study Design and Study Population:}

In this retrospective (historical) cohort study, the study population was all people exposed to mustard gas in sardasht in 1987 based on the approval of the VMAF (the Veterans and Martyr Affair Foundation). VMAF is the legal authority in Iran that provides pension and health services to war survivor. This foundation registered all survivors of war and then regularly provides long-term care services to them and their families by maintaining excellence in health care services through professional collaboration $[6,8]$. Therefore, the inclusion criterion was the approval of the Veterans and Martyr Affair Foundation of Iran to contact of the persons with the chemical agent of mustard gas and the exclusion criterion was the occurrence of premature death. According to the contract in this study, premature death refers to death at the time of exposure (during the first 14 days after exposure).

\subsection{Data Collection:}

Data related to health status (death / life) and other information related to the subjects were obtained by referring to the Veterans and Martyr Affair Foundation of Iran and reviewing the VMAF database up to 
March 20, 2019. Normally, all information related to the deaths of war survivors in Iran is transferred to the Veterans and Martyr Affair Foundation of Iran, where a death commission consisting of various specialists and experts investigates the causes of death. The members of this committee are aware of the possible chronic effects of mustard gas and determine the causes of death based on the medical record and death certificate.

In addition to data on the health status (death / life) of the subjects, other information included gender (male / female), age of the person at the time of exposure, severity of late complication (no symptom, mild symptom, moderate symptom, severe symptom), organ of the late complication (lung, Eyes, skin) beside evacuation and hospital admission status (EA, NEA, None) were also taken from the mentioned database and recorded. In order to classified subject according to evacuation and hospital admission, based on the evidence of exposure to MG, the data were categorized into 3 groups: (1) evacuated and admitted (EA), confirmed history of exposure in the affected geographic region with evacuation and hospital admission; (2) not evacuated or admitted (NEA), confirmed history of exposure without evacuation or hospital admission; and (3) undocumented cases, not classified in the other 2 groups but showing late clinical manifestations suggestive of exposure. The classification criterion for the severity of the late complication which periodically examined and record by a specialized medical team was based on the protocol compiled by a panel of experts at the Veterans and Martyr Affair Foundation of Iran. Based on this protocol, the complications in these people are divided into four categories: no symptom, mild, moderate and severe symptom. The panel included pulmonologists, psychiatrists, neurologists, ophthalmologists, dermatologists, cardiologists, forensic specialists and nephrologists, reviewed the relevant documents and evidence and categorized them [6]. Definition of late complications in lung, skin and eye were as follow:

\section{Lungs:}

Categorization of complication in lung following MG exposure was defined using spirometry results of forced expiratory volume in the first second (FEV1) as follow: no symptoms, FEV1 higher than $80 \%$; mild, FEV1 higher than $70 \%$ but lower than or equal to $80 \%$; moderate, FEV1 higher than $50 \%$ but lower than or equal to $70 \%$; and severe, FEV1 lower than or equal to $50 \%$ with normal arterial blood gas or severe tracheabronchomalacia $[6,9]$.

Skin:

Category of skin complications subsequent exposure to MG was determined as follows: Mild category was defined as the presence of an MG-specific scar (pigmentation, vascular, or trophic changes) across less than $5 \%$ of the body surface; the presence of such a scar plus mild dermatitis and mild xerosis or mild-to-moderate autoimmune diseases; and concurrent medical documents plus severe autoimmune diseases or any mild dermatitis. The moderate category was defined as the presence of an MG-specific scar affecting between $5 \%$ and $20 \%$ of the body surface2; presence of an MG-specific scar with significant trophic changes in the genital or anus areas; the presence of an MG-specific scar of any size with or without concurrent medical documents plus severe dermatitis covering less than $50 \%$ of the body 
surface; concurrent medical documents with severe dermatitis or xerosis covering less than $50 \%$ of the body surface; and the presence of an MG-specific scar of any size with or without concurrent medical documents plus any severe autoimmune disease affecting the skin covering more than $50 \%$ of the body surface. The severe category was defined as the presence of an MG-specific scar covering more than $20 \%$ of the body surface; the presence of an MG-specific scar of any size with or without concurrent medical documents with severe dermatitis or xerosis covering more than $50 \%$ of the body surface; and concurrent medical documents with severe dermatitis or xerosis covering less than $50 \%$ of the body surface $[6,10]$.

Eyes:

Complication in eye following MG exposure was categorized as follow: Mild category was defined as burning, itching, tearing, redness, foreign body sensation, blurred vision, conjunctivitis, subconjunctival hemorrhage, photophobia, or conjunctival vascular changes (telangiectasia and vascular changes, edema of the eyelid, papillary changes) of 1 or both eyes. The moderate category was defined as the same changes in the mild category along with conjunctival ischemia in the limbus area, as well as unilateral or bilateral closure or cauterization of punctum. The severe category was defined as those observations in the moderate category along with symptoms of corneal involvement, epithelial and subepithelial opacity and anterior stroma in the cornea, keratopathy, pannus, hyperpigmentation around the nerve, iron deposition in the cornea and corneal vascularization, stenosis, and involvement of less than half unilaterally or bilaterally in both eyes $[6,11]$.

\subsection{Statistical Analysis:}

After collecting data, all statistical analyzes were performed in Stata software version 15. At first, the frequency and relative frequency index was used to express the basic characteristics of the subjects.

In order to describe the mortality in the cohort, we used cumulative mortality rate and mortality rate index. To calculate mortality rate index we first calculated the person-years at risk in these individuals from the time of exposure to mustard gas to the occurrence of death in the case of subject who died, or at the end of follow up for other subject. Then all-cause mortality rate and the cause-specific mortality rate were calculated.

In order to compare the mortality in the cohort with the general population (Iran), we used standardized mortality ratio (SMR) index. SMR is the number of observed deaths divided by the expected death. To calculate expected death, first, mortality rate of the general population according to sex, age (5 year age group) and calendar year were obtained using the information published by GBD 2019 Demographics Collaborators [12]. Then expected death was determined by multiplying the mortality rate of the general population and the person-years of the cohort. Finally we calculated all-cause SMR and cause-specific SMR. Also, all-cause SMR was determined according to age, sex and severity of late complication. For 
each SMR, a 95\% confidence interval was calculated according to the assumption that the number of deaths observed follows the Poisson distribution.

Eventually, cox regression model was used to determine the relationship between the independent variables (age at time of exposure, sex, severity of late complication, evacuation and hospital admission Status) and risk of death. To do this, first, the univariate Cox regression model was used and the variables that had a significance level of less than 0.1 in this model were included in the multivariate Cox regression model. Finally, variables that had a significance level of less than 0.05 in the multiple models were considered as a factor affecting the risk of death in the cohort.

\section{Results:}

\subsection{Basic characteristics of people exposed to mustard gas in Sardasht}

The results of this study on people exposed to mustard gas in Sardasht, showed that most of the cohort subject at the time of exposure, was less than 40 years old, in other words, $85.7 \%$ of people at the time of exposure, had age less than 40 years. The average age of people at the time of exposure was 25.51 . The results also showed that most of the subjects were male (60.5\%) and $39.5 \%$ were female. The full result of basic characteristic of the subject including age at time of exposure, sex, severity of late complications beside evacuation and hospital admission status were presented in Table 1.

\subsection{Mortality of people exposed to mustard gas in Sardasht and its comparison with the general population}

The results of the study concerning mortality in the subjects from July 28, 1987 to March 20, 2019 showed that the total cumulative mortality rate during this period was equal to $12.30 \%$. In other words, among the people who were exposed to MG at the beginning of the study, $12.30 \%$ of them $(1203 / 148)$ died by the end of study. Also, mortality rate between these years was 387 per 100,000 person-years. In other words, 148 deaths per 38198.63 person-years occurred in this study. The average age of the died people at the time of death was 66.42 . In addition, the results showed that out of these 148 deaths, 72 had unknown causes and the cause of death of 76 people was determined, among which the most cases were due to cardiovascular diseases with 33 cases and respiratory diseases with 26 cases. The complete results concerning mortality in the subject was shown in Table 2.

The results of comparing the mortality in the study population with general population (Iran) were shown in Table 3. Based on the results, all-cause standardized mortality ratio index was 0.680 . In other words, the expected mortality for the study population was 217.65 , while the observed number of deaths in this population was 148 . Also, the all-cause standardized mortality rate according to sex, age at the time of exposure, year, and severity of the late complication beside evacuation and hospital admission status as well as cause-specific mortality ratio were calculated and expressed in Tables 2 and 3 . This result showed 
that people with severe late lung complication had almost twice as many deaths as expected (SMR: 2.433) and People with severe late skin complication were also more likely to die than expected (SMR: 1.241). In addition, determining cause-specific standardized mortality ratio showed that observed death due to respiratory diseases was higher than expected (SMR: 1.75).

The results of Cox regression analysis to determine effect of age at time of exposure, sex and severity of late complication beside evacuation and hospital admission status on mortality in the subjects showed that sex was not related to the risk of mortality in these individuals, while there was a significant relationship between age at time of exposure with risk of death (HR: 1.077) and severity of lung complication with the risk of death (HR: 5.954). The complete results of Cox regression analysis were presented in Tables 4 and 5. Subsequently, cumulative death rate curve for the variables of age at time of exposure and severity of lung complication was obtained using Kaplan Meyer analysis method and was presented in Figs. 1 and 2. 
Table 1

Basic Characteristics of People Exposed To MG in Sardasht, Iran

\begin{tabular}{|c|c|c|c|c|c|}
\hline & & & & Frequency & $\begin{array}{l}\text { Relative } \\
\text { frequency }\end{array}$ \\
\hline \multirow{3}{*}{\multicolumn{2}{|c|}{ Age at Exposure Time }} & \multicolumn{2}{|c|}{ Under 20} & 487 & 40.5 \\
\hline & & \multicolumn{2}{|c|}{$20-40$} & 543 & 45.1 \\
\hline & & \multicolumn{2}{|c|}{ Above 40} & 173 & 14.4 \\
\hline \multirow{2}{*}{\multicolumn{2}{|c|}{ Sex }} & \multicolumn{2}{|l|}{ Male } & 728 & 60.5 \\
\hline & & \multicolumn{2}{|c|}{ Female } & 475 & 39.5 \\
\hline \multirow{12}{*}{$\begin{array}{l}\text { Severity of late complication in } \\
\text { different organ }\end{array}$} & \multirow[t]{4}{*}{ Lung } & \multicolumn{2}{|c|}{ No Symptom } & 378 & 31.4 \\
\hline & & \multicolumn{2}{|l|}{ Mild } & 633 & 52.6 \\
\hline & & \multicolumn{2}{|c|}{ Moderate } & 169 & 14 \\
\hline & & \multicolumn{2}{|l|}{ Sever } & 23 & 2 \\
\hline & \multirow[t]{4}{*}{ Skin } & \multicolumn{2}{|c|}{ No Symptom } & 916 & 76.1 \\
\hline & & \multicolumn{2}{|l|}{ Mild } & 238 & 19.8 \\
\hline & & \multicolumn{2}{|c|}{ Moderate } & 43 & 3.6 \\
\hline & & \multicolumn{2}{|l|}{ Sever } & 6 & 0.5 \\
\hline & \multirow[t]{4}{*}{ Eye } & \multicolumn{2}{|c|}{ No Symptom } & 994 & 82.6 \\
\hline & & \multicolumn{2}{|l|}{ Mild } & 198 & 16.5 \\
\hline & & \multicolumn{2}{|c|}{ Moderate } & 10 & 0.8 \\
\hline & & \multicolumn{2}{|l|}{ Sever } & 1 & 0.1 \\
\hline \multirow{2}{*}{\multicolumn{2}{|c|}{ Evacuation and Hospital Admission Status }} & \multicolumn{2}{|l|}{ EA } & 416 & 34.6 \\
\hline & & \multicolumn{2}{|l|}{ NEA } & 787 & 65.4 \\
\hline \multirow{3}{*}{\multicolumn{2}{|c|}{ Current Health Status }} & \multicolumn{2}{|l|}{ Alive } & 1055 & 87.69 \\
\hline & & \multirow[t]{2}{*}{ Dead } & $\begin{array}{l}\text { Known } \\
\text { cause }\end{array}$ & 76 & 6.32 \\
\hline & & & $\begin{array}{l}\text { Unknown } \\
\text { cause }\end{array}$ & 72 & 5.99 \\
\hline
\end{tabular}


Table 2

All-Cause and Cause-Specific SMR among People Exposed to MG in Sardasht, Iran

\begin{tabular}{|c|c|c|c|c|c|c|c|}
\hline & $\begin{array}{l}\text { ICD } \\
10\end{array}$ & $\begin{array}{l}\text { Observed } \\
\text { Death }\end{array}$ & $\begin{array}{l}\text { Mortality } \\
\text { Rate }\end{array}$ & $\begin{array}{l}\text { Cumulative } \\
\text { Mortality Rate }\end{array}$ & $\begin{array}{l}\text { Expected } \\
\text { Death }\end{array}$ & SMR & $\begin{array}{l}\text { SMR } \\
\text { (95\% } \\
\text { Cl) }\end{array}$ \\
\hline All Cause & $\begin{array}{l}\text { A00- } \\
\text { Z99 }\end{array}$ & 148 & 0.00387 & 0.123 & 217.65 & 0.680 & $\begin{array}{l}0.574- \\
0.798\end{array}$ \\
\hline Neoplasm & $\begin{array}{l}\text { C00- } \\
\text { D49 }\end{array}$ & 9 & 0.00023 & 0.0075 & 36.70 & 0.245 & $\begin{array}{l}0.112- \\
0.465\end{array}$ \\
\hline $\begin{array}{l}\text { Circulatory } \\
\text { System Disease }\end{array}$ & $\begin{array}{l}100- \\
199\end{array}$ & 33 & 0.00086 & 0.0274 & 98.65 & 0.335 & $\begin{array}{l}0.230- \\
0.469\end{array}$ \\
\hline $\begin{array}{l}\text { Respiratory } \\
\text { System Disease }\end{array}$ & $\begin{array}{l}\text { J00- } \\
\text { J99 }\end{array}$ & 26 & 0.00068 & 0.0216 & 14.83 & 1.753 & $\begin{array}{l}1.145- \\
2.569\end{array}$ \\
\hline $\begin{array}{l}\text { Genitourinary } \\
\text { System Disease }\end{array}$ & $\begin{array}{l}\text { N00- } \\
\text { N99 }\end{array}$ & 3 & 0.000078 & 0.0025 & 6.57 & 0.457 & $\begin{array}{l}0.094- \\
1.334\end{array}$ \\
\hline External Cause & $\begin{array}{l}\text { S00- } \\
\text { Y88 }\end{array}$ & 5 & 0.00038 & 0.0041 & 34.12 & 0.147 & $\begin{array}{l}0.047- \\
0.341\end{array}$ \\
\hline
\end{tabular}


Table 3

All-Cause SMR among People Exposed to MG in Sardasht, Iran according to Independent Variable

\begin{tabular}{|c|c|c|c|c|c|c|c|}
\hline & & & $\begin{array}{l}\text { Person- } \\
\text { Years }\end{array}$ & $\begin{array}{l}\text { Observed } \\
\text { Death }\end{array}$ & $\begin{array}{l}\text { Expected } \\
\text { Death }\end{array}$ & SMR & $\begin{array}{l}\text { SMR } \\
(95 \% \\
\mathrm{Cl})\end{array}$ \\
\hline Total & & & 38198.63 & 148 & 217.65 & 0.680 & $\begin{array}{l}0.574- \\
0.798\end{array}$ \\
\hline \multirow{3}{*}{\multicolumn{2}{|c|}{ Age at Exposure Time }} & Under 20 & 15838.86 & 12 & 22.78 & 0.526 & $\begin{array}{l}0.272- \\
0.922\end{array}$ \\
\hline & & $20-40$ & 17417.25 & 54 & 65.35 & 0.826 & $\begin{array}{l}0.621- \\
01.079\end{array}$ \\
\hline & & Above 40 & 4942.52 & 82 & 129.50 & 0.633 & $\begin{array}{l}0.503- \\
0.786\end{array}$ \\
\hline \multirow{2}{*}{\multicolumn{2}{|c|}{ Sex }} & Male & 15262.03 & 45 & 62.75 & 0.717 & $\begin{array}{l}0.523- \\
0.959\end{array}$ \\
\hline & & Female & 22936.60 & 103 & 154.90 & 0.665 & $\begin{array}{l}0.542- \\
0.806\end{array}$ \\
\hline \multirow{7}{*}{\multicolumn{2}{|c|}{ Years }} & $\begin{array}{l}1987- \\
1990\end{array}$ & 4219.68 & 0 & 15.94 & 0 & $\begin{array}{l}0- \\
0.231\end{array}$ \\
\hline & & $\begin{array}{l}1991- \\
1995\end{array}$ & 6024.19 & 0 & 20.49 & 0 & $\begin{array}{l}0- \\
0.180\end{array}$ \\
\hline & & $\begin{array}{l}1996- \\
2000\end{array}$ & 6020.38 & 9 & 29.01 & 0.310 & $\begin{array}{l}0.141- \\
0.588\end{array}$ \\
\hline & & $\begin{array}{l}2001- \\
2005\end{array}$ & 6016.19 & 20 & 32.35 & 0.618 & $\begin{array}{l}0.377- \\
0.954\end{array}$ \\
\hline & & $\begin{array}{l}2006- \\
2010\end{array}$ & 6007.68 & 39 & 39.90 & 0.977 & $\begin{array}{l}0.695- \\
1.336\end{array}$ \\
\hline & & $\begin{array}{l}2011- \\
2015\end{array}$ & 6006.68 & 43 & 45.44 & 0.946 & $\begin{array}{l}0.684- \\
1.274\end{array}$ \\
\hline & & $\begin{array}{l}2016- \\
2019\end{array}$ & 3903.83 & 36 & 34.53 & 1.042 & $\begin{array}{l}0.730- \\
1.443\end{array}$ \\
\hline \multirow{4}{*}{$\begin{array}{l}\text { Severity of late } \\
\text { complication in } \\
\text { different organ }\end{array}$} & \multirow[t]{4}{*}{ Lung } & $\begin{array}{l}\text { No } \\
\text { Symptom }\end{array}$ & 12040.78 & 41 & 60.99 & 0.672 & $\begin{array}{l}0.483- \\
0.913\end{array}$ \\
\hline & & Mild & 20238.39 & 64 & 112.66 & 0.568 & $\begin{array}{l}0.437- \\
0.726\end{array}$ \\
\hline & & Moderate & 5305.31 & 31 & 38.94 & 0.796 & $\begin{array}{l}1.133- \\
0.542\end{array}$ \\
\hline & & Sever & 614.15 & 12 & 5.06 & 2.371 & $\begin{array}{l}4.250- \\
1.257\end{array}$ \\
\hline
\end{tabular}




\begin{tabular}{|c|c|c|c|c|c|c|c|}
\hline & & & $\begin{array}{l}\text { Person- } \\
\text { Years }\end{array}$ & $\begin{array}{l}\text { Observed } \\
\text { Death }\end{array}$ & $\begin{array}{l}\text { Expected } \\
\text { Death }\end{array}$ & SMR & $\begin{array}{l}\text { SMR } \\
\text { (95\% } \\
\text { Cl) }\end{array}$ \\
\hline & \multirow[t]{4}{*}{ Skin } & $\begin{array}{l}\text { No } \\
\text { Symptom }\end{array}$ & 29166.51 & 105 & 152.18 & 0.689 & $\begin{array}{l}0.564- \\
0.835\end{array}$ \\
\hline & & Mild & 7496.99 & 35 & 56.54 & 0.619 & $\begin{array}{l}0.431- \\
0.862\end{array}$ \\
\hline & & Moderate & 1339.96 & 7 & 8.01 & 0.873 & $\begin{array}{l}1.823- \\
0.355\end{array}$ \\
\hline & & Sever & 195.17 & 1 & 0.91 & 1.098 & $\begin{array}{l}6.916- \\
0.031\end{array}$ \\
\hline & \multirow[t]{4}{*}{ Eye } & $\begin{array}{l}\text { No } \\
\text { Symptom }\end{array}$ & 31574.67 & 117 & 171.17 & 0.683 & $\begin{array}{l}0.565- \\
0.819\end{array}$ \\
\hline & & Mild & 6272.75 & 30 & 44.35 & 0.676 & $\begin{array}{l}0.457- \\
0.968\end{array}$ \\
\hline & & Moderate & 318.46 & 1 & 1.90 & 0.526 & $\begin{array}{l}3.158- \\
0.014\end{array}$ \\
\hline & & Sever & 32.75 & 0 & 0.23 & 0 & 0 \\
\hline \multirow{2}{*}{\multicolumn{2}{|c|}{$\begin{array}{l}\text { Evacuation and Hospital } \\
\text { Admission Status }\end{array}$}} & EA & 12969.08 & 73 & 96.80 & 0.754 & $\begin{array}{l}0.591- \\
0.949\end{array}$ \\
\hline & & NEA & 25229.55 & 75 & 120.85 & 0.620 & $\begin{array}{l}0.488- \\
0.778\end{array}$ \\
\hline
\end{tabular}


Table 4

Univariate Cox proportional hazards regression: factors associated with death in the People Exposed to MG in Sardasht, Iran

\begin{tabular}{|c|c|c|c|c|c|}
\hline & & B & HR & $\mathrm{HR}(95 \% \mathrm{Cl})$ & $\begin{array}{l}\mathrm{P} \\
\text { Value }\end{array}$ \\
\hline \multirow[t]{2}{*}{ Sex } & Male & 0.438 & 1.549 & $1.091-2.198$ & 0.014 \\
\hline & Female & & & & \\
\hline Age at Exposure Time & & 0.075 & 1.078 & $1.066-1.086$ & 0.000 \\
\hline \multirow[t]{4}{*}{ Severity of Late Complication in Lung } & $\begin{array}{l}\text { No } \\
\text { Symptom }\end{array}$ & & & & \\
\hline & Mild & $\overline{0} .077$ & 0.925 & $0.625-1.369$ & 0.699 \\
\hline & Moderate & 0.556 & 1.744 & $1.093-2.779$ & 0.019 \\
\hline & Sever & 1.954 & 7.057 & $\begin{array}{l}3.706- \\
13.437\end{array}$ & 0.000 \\
\hline \multirow[t]{4}{*}{ Severity of Late Complication in Skin } & $\begin{array}{l}\text { No } \\
\text { Symptom }\end{array}$ & & & & \\
\hline & Mild & 0.275 & 1.316 & $0.897-1.929$ & 0.160 \\
\hline & Moderate & 0.391 & 1.479 & $0.688-3.179$ & 0.316 \\
\hline & Sever & 0.332 & 1.393 & $0.194-9.984$ & 0.741 \\
\hline \multirow[t]{4}{*}{ Severity of Late Complication in Eye } & $\begin{array}{l}\text { No } \\
\text { Symptom }\end{array}$ & & & & \\
\hline & Mild & 0.260 & 1.297 & $0.868-1.937$ & 0.203 \\
\hline & Moderate & -0.168 & 0.846 & $0.118-6.054$ & 0.867 \\
\hline & Sever & - & - & - & - \\
\hline \multirow{2}{*}{$\begin{array}{l}\text { Evacuation and Hospital Admission } \\
\text { Status }\end{array}$} & EA & & & & \\
\hline & NEA & -0.666 & 0.514 & $0.372-0.708$ & 0.000 \\
\hline
\end{tabular}


Table 5

Multivariate Cox proportional hazards regression: factors associated with death in the People Exposed to MG in Sardasht, Iran

\begin{tabular}{|c|c|c|c|c|c|}
\hline & & B & HR & $\mathrm{HR}(95 \% \mathrm{Cl})$ & $\begin{array}{l}\mathrm{P} \\
\text { Value }\end{array}$ \\
\hline \multirow[t]{2}{*}{ Sex } & Male & 0.194 & 1.214 & $\begin{array}{l}0.850- \\
1.734\end{array}$ & 0.286 \\
\hline & Female & & & & \\
\hline Age at Exposure Time & & 0.074 & 1.077 & $\begin{array}{l}1.066- \\
1.087\end{array}$ & 0.000 \\
\hline \multirow[t]{4}{*}{ Severity of Late Complication in Lung } & $\begin{array}{l}\text { No } \\
\text { Symptom }\end{array}$ & & & & \\
\hline & Mild & -0.139 & 0.870 & $\begin{array}{l}0.572- \\
1.322\end{array}$ & 0.516 \\
\hline & Moderate & 0.277 & 1.319 & $\begin{array}{l}0.821- \\
2.117\end{array}$ & 0.252 \\
\hline & Sever & 1.784 & 5.954 & $\begin{array}{l}3.036- \\
11.676\end{array}$ & 0.000 \\
\hline \multirow{2}{*}{$\begin{array}{l}\text { Evacuation and Hospital Admission } \\
\text { Status }\end{array}$} & EA & & & & \\
\hline & NEA & -0.054 & 0.947 & $\begin{array}{l}0.645- \\
1.389\end{array}$ & 0.947 \\
\hline
\end{tabular}

\section{Discussion:}

This study, for the first time, investigate the mortality rate of people exposed to mustard gas in the city of Sardasht, which was bombard by seven mustard gas $250 \mathrm{~kg}$ bombs during the Iran-Iraq war. The results of this study are important because the exposed people in sardasht, unlike other similar studies, are civilian people, so they have similar characteristics to the general population and on the other hand they had no protective clothing and masks to deal with this agent.

The results of this study on all-cause mortality and its comparison with the general Iranian population showed that mortality rate in people exposed to mustard gas in Sardasht city did not increase after 32 years, indeed observed death was remarkable lower than expected death (SMR: 0.687). Most of the similar studies have focused on the impact of chronic exposure or on the impact of acute exposure on cause-specific mortality. However, in a similar study concerning impact of acute mustard gas exposure on all-cause mortality, Norman et all, was selected a sample of 2718 men admitted to American special gas hospitals in August and October 1918 at the end of world war I with clear evidence of mustard gas exposure. Then they compared mortality of the cohort to the general population (US white male population) from 1918 to 1965 and indicate that observed death is very close to expected death after 47 years (SMR: 0.99) [3]. Whereas, in the present study, although the subject were civilians who had no 
protective clothing and masks to deal with this agent, the number of deaths observed was remarkable lower than expected. As an explanation, we believe that the result of the current study can be due to the provision of immediate and special care under the national care management scheme. As in a study, Mokida et al. in Japan compared the mortality of people exposed to mustard gas in factory workers to the general Japanese population after 57 years, and they also showed that there were a lower number of observed deaths than the number of expected deaths. They attributed the reason to the receipt of special health care beside existence of a healthy worker effect [4]. However, in our study the role of receiving special health care is much more obvious, because the study mentioned in Japan was on factory workers, while the current study was on the civilian, and here we do not have a healthy worker and we can attribute this reduction in mortality to the role of receiving special health care with more certainty. As a further explanation, other studies have highlighted receiving good special services for war survivor in Iran. For example study by Mousavi et al, indicated that health care utilization (outpatient and inpatient) are more frequent among war survivors compared to the general Iranian population. [13].

Besides, all-cause standardized mortality ratio according to the severity of late complication showed that in individuals with severe lung complication and severe skin complication the observed death was much higher than expected. Of course, it should be noted that the severe skin complication was slightly more than expected, while for severe lung complication was more than twice the expected amount. Moreover, cox regression indicated that only severe lung complication increased risk of death in the cohort. There has been a lack of similar studies addressing long term mortality according to severity of late complication. However, this result indicated that when subject categorized according to severity of late complication, only sever complication especially severe lung complication affected all-cause mortality. Various studies have shown that the severity of the complication, especially lung complication in people exposed to mustard gas can become more severe over time [14,15]. Even evidence has shown that people who were exposed to low doses of mustard gas and did not have acute clinical symptoms such as blisters also developed pulmonary bronchiolitis complications over time [16]. Therefore, preventing the progression of respiratory complication to sever complication in people affected by mustard gas using early detection is very important and can improve the survival of the injured.

In this study, we also investigated the causes of deaths in this population and compare it with Iranian national population using cause-specific SMR. It is necessary to mention that because of ethical restrictions no autopsy was performed to determine the cause of death. Therefore, unfortunately, in this study, we did not have the cause of almost $45 \%$ of deaths. Nevertheless, the results showed that in the case of respiratory diseases, unlike other diseases, the observed death was higher than expected. It is well known that pulmonary injury is the principal cause of mortality in the first few days to weeks after intense exposure to sulfur mustard. Also, the existence evidence indicates a causal relation between both acute and chronic exposure to sufficient concentrations of sulfur mustard and long-term mortality due to malignant respiratory and none-malignant respiratory disease specially bronchitis which is consistent with our result $[3,7,17]$. Of course, it is important to note that despite the evidence for a relation between the both exposure and long-term mortality due to malignant respiratory disease, chronic exposure has been shown to be carcinogenic, while there is still doubt about carcinogenicity of acute exposure. In other 
words, studies have reported an association between acute exposure and mortality from respiratory disease cancer did not interpret this exposure as carcinogenic and interpret that increase in other lung diseases, such as bronchitis led to cancer. In the present study, we also observed excess death only due to non-malignant respiratory diseases $[3,7,18]$. Therefore, considering the above, the increase in mortality due to respiratory diseases can be justified. However, despite increasing mortality due to respiratory disease, all-cause mortality rate has not increased. In fact, this was partly because most of these people had mild to moderate lung complications. As we have shown, only severe lung complications can affect all-cause mortality, while there was a low percent of the subject with severe lung complications in sardasht and therefore all-cause mortality was not affected. It should be noted that, low percent of severe lung cases may have been due in part to special care. Moreover, special care has reduced diseases and disorders in other organs such as the circulatory system which almost is the leading cause of death and thereby reducing overall mortality. As exciting evidence have shown, even in people with lung involvement such as COPD and asthma, circulatory disease is the leading cause of death, and an increase in respiratory deaths without an increase in deaths due to circulatory system, can rarely affect total deaths [19]. Therefore, in this study, exposure to mustard gas, despite involving the lungs and increasing respiratory mortality, has not been increase all-cause mortality rate due to the control of circulatory disease and other leading cause of death.

One of the strengths of this study is the high sample size. It can also be noted that this is the first study to investigate the effects of acute mustard gas exposure in a population with similar characteristics to the general population. In this study, we also included all people who were exposed to mustard gas in the city of Sardasht. In addition, other strength of this study is the duration of the study, which was included approximately 32 years after the exposure time. Limitation of this study was that we were not allowed to use autopsy to determine the cause of death; resultantly, the cause of death in approximately $45 \%$ of deaths were unknown. Nevertheless, it should be noted that even if all the death causes were known, mortality rate due to all-cause would definitely be lower than expected, and the respiratory mortality would certainly be higher than expected.

\section{Conclusion:}

Overall, this study showed that although exposure to mustard gas, which specifically caused injury in respiratory system and lung, has increased mortality rate due to respiratory diseases in exposed people in sardasht in Iran after 32 years, but all-cause mortality rate did not increase in this period. This indicates the impact of special care measures on these individuals immediately after exposure which prevented disease and disorder specifically in circulatory system and consequently reduced total number of death in long-term. Indeed, this result indicates that acute exposure to mustard gas, even without wearing protective clothing and masks to deal with this agent., will not increase all-cause mortality rate after 32 years if accompanied by special and ongoing care for those exposed. This study can be informative that exposure to any chemical agent which causes respiratory complications may not increase long-term mortality, if accompanied by special and ongoing care. 


\section{Abbreviations:}

MG: Mustard Gas

SMR: Standard Mortality Ratio

VMAF: Veterans and Martyr Affair Foundation

$\mathrm{FEV}_{1}$ : Forced Expiratory Volume in the First Second

HR: Hazard Ratio

COPD: Chronic Obstructive Pulmonary Disease

\section{Declarations:}

\section{Availability of data and materials:}

The dataset supporting the conclusions of this article is available in the Veterans and Martyr Affair Foundation of Iran. Restrictions apply to the availability of the data from VMAF of Iran, which were used under license for the current study, and so are not publicly available. All our analyses were performed within strict privacy rules; that is, only researchers who received a signed permit were allowed to do analyses within a secured environment.

\section{Acknowledgment:}

Not Applicable

\section{Funding:}

The authors received no specific funding for this work

\section{Author contribution:}

M.GH participated in study design. MH.R and H.A did data acquisition and analyzed the data. MH.R and M.GH drafted the manuscript. Review and editing of the manuscript were done by M.GH, M.H.R, H.A and A.A. All authors approved the final draft for publication.

\section{Ethics approval and consent to participate}

This study waived the need for obtaining informed consent because this study used non-identifiable data from an existing data set.

\section{Consent for publication}

Not applicable. 
Competing interests

The authors declare that they have no competing interests

\section{References:}

1. Bullman T, Kang H: A Fifty Year Mortality Follow-up Study of Veterans Exposed to Low Level Chemical Warfare Agent, Mustard Gas.Annals of Epidemiology 2000, 10:333-338.

2. Ghazanfari T, Faghihzadeh S, Aragizadeh H, Soroush M, Yaraee R, Hassan ZM, Foroutan A, vaez Mahdavi MR, Javadi M-A, Moaiedmohseni S, et al: Sardasht-Iran Cohort Study of Chemical Warfare Victims: Design and Methods.Archives of Iranian medicine 2009, 12:5-14.

3. Norman JE, Jr.: Lung Cancer Mortality in World War I Veterans With Mustard-Gas Injury: 191919652.JNCl: Journal of the National Cancer Institute 1975, 54:311-317.

4. Mukaida K, Hattori N, Iwamoto H, Onari Y, Nishimura Y, Kondoh K, Akita T, Tanaka J, Kohno N: Mustard gas exposure and mortality among retired workers at a poisonous gas factory in Japan: A 57-year follow-up cohort study.Occupational and Environmental Medicine 2016, 74:oemed-2015.

5. Wattana M, Bey T: Mustard Gas or Sulfur Mustard: An Old Chemical Agent as a New Terrorist Threat.Prehospital and Disaster Medicine 2012, 24:19-29.

6. Amini H, Solaymani-Dodaran M, Mousavi B, Alam Beladi SN, Soroush MR, Abolghasemi J, VahedianAzimi A, Salesi M, Guest PC, Sahebkar A, Ghanei M: Long-term Health Outcomes Among Survivors Exposed to Sulfur Mustard in Iran.JAMA Network Open 2020, 3:e2028894-e2028894.

7. Case RAM, Lea AJ: Mustard Gas Poisoning, Chronic Bronchitis, and Lung Cancer.British Journal of Preventive \&amp;amp; Social Medicine 1955, 9:62.

8. Soroush M, Ganjparvar Z, Mousavi B: Human Casualties and War: Results of a National Epidemiologic Survey in Iran.Arch Iran Med 2020, 23:S33-S37.

9. Cui Y, Dai Z, Luo L, Chen P, Chen Y: Classification and treatment of chronic obstructive pulmonary disease outpatients in China according to the Global Initiative for Chronic Obstructive Lung Disease (GOLD) 2017: comparison with GOLD 2014.Journal of Thoracic Disease 2019, 11:1303-1315.

10. Poursaleh Z, Ghanei M, Babamahmoodi F, Izadi M, Harandi AA, Emadi SE, Taghavi Nh-o-S, SayadNouri SS, Emadi SN: Pathogenesis and treatment of skin lesions caused by sulfur mustard.Cutaneous and Ocular Toxicology 2012, 31:241-249.

11. Ghasemi H, Ghazanfari T, Ghassemi-Broumand M, Javadi MA, Babaei M, Soroush MR, Yaraee R, Faghihzadeh S, Poorfarzam S, Owlia P, et al: Long-term ocular consequences of sulfur mustard in seriously eye-injured war veterans.Cutaneous and Ocular Toxicology 2009, 28:71-77.

12. Collaborators GD: Global age-sex-specific fertility, mortality, healthy life expectancy (HALE), and population estimates in 204 countries and territories, 1950-2019: a comprehensive demographic analysis for the Global Burden of Disease Study 2019. The Lancet 2020, 396:1160-1203. 
13. Mousavi B, Maftoon F, Soroush M, Mohammad K, Majdzadeh R: Health Care Utilization and Expenditure in War Survivors.Arch Iran Med 2020, 23:S9-S15.

14. Ghanei M, Adibi I, Farhat F, Aslani J: Late respiratory effects of sulfur mustard: how is the early symptoms severity involved? Chronic Respiratory Disease 2008, 5:95-100.

15. Balali-Mood M, Hefazi M: Comparison of Early and Late Toxic Effects of Sulfur Mustard in Iranian Veterans.Basic \& clinical pharmacology \& toxicology 2006, 99:273-282.

16. Poursaleh Z, Ghaneei M, Naderi M, Amini Harandi A: Chronic Pulmonary Complications in IraqKurdistan Chemical Weapons Victims.Journal of Military Medicine 2011, 13:37-42.

17. Institute of Medicine (US) Committee on the Survey of the Health Effects of Mustard Gas and Lewisite; Pechura CM RD, editors: Veterans at Risk: The Health Effects of Mustard Gas and Lewisite. Washington (DC): National Academies Press (US); 1993.

18. Panahi Y, Gholami N, Ghojazadeh M, Moslemi F, Naghavi-Behzad M, Azami-Aghdash S, Ghaffari A, Piri R: Complications and Carcinogenic Effects of Mustard Gas - a Systematic Review and MetaAnalysis in Iran.Asian Pacific journal of cancer prevention : APJCP 2015, 16:7567-7573.

19. Finkelstein MM, Chapman KR, Mclvor RA, Sears MR: Mortality among subjects with chronic obstructive pulmonary disease or asthma at two respiratory disease clinics in Ontario.Canadian respiratory journal 2011, 18:327-332.

\section{Figures}

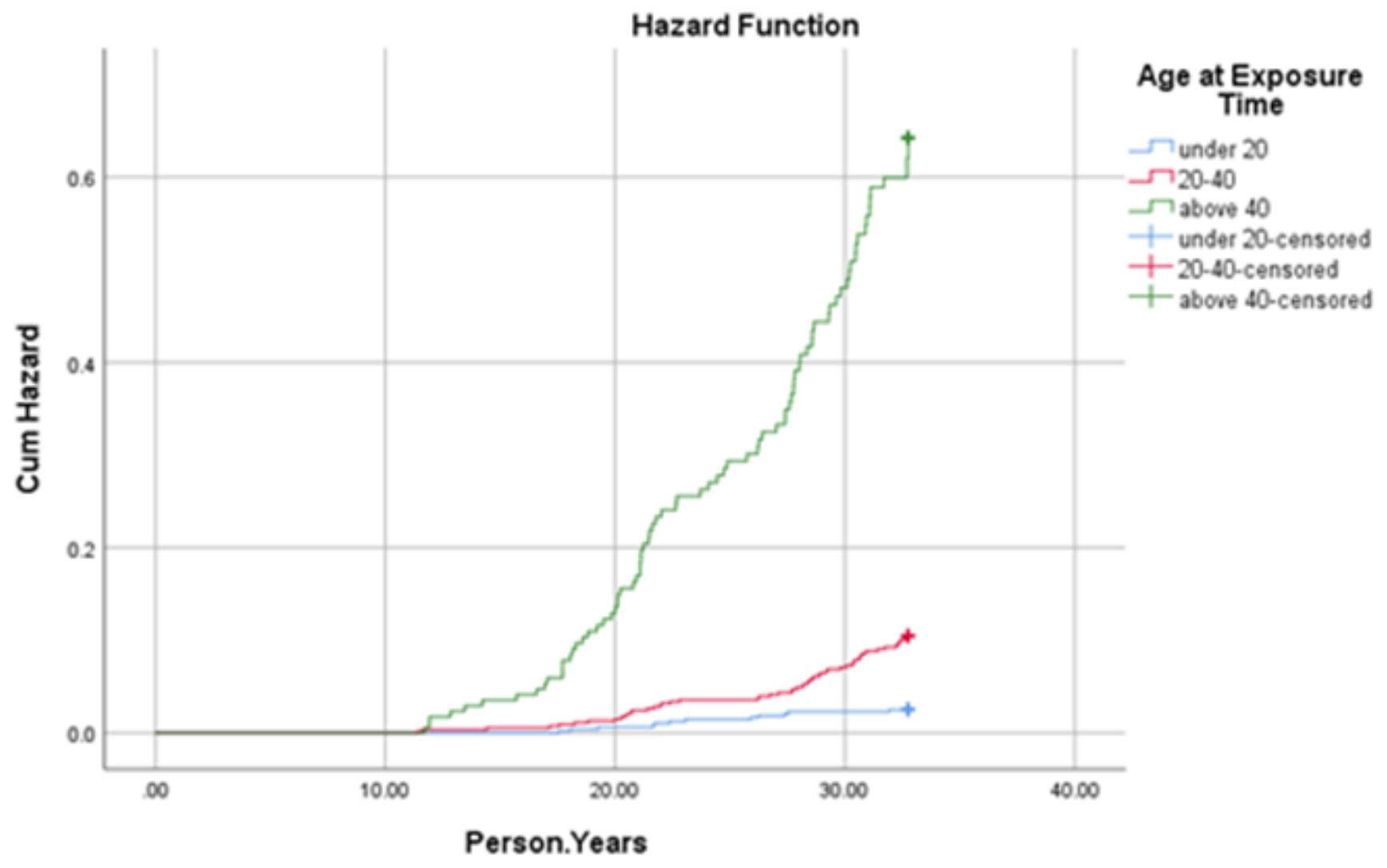


Figure 1

Cumulative death rates in the People Exposed to MG in Sardasht, Iran Stratified by Age

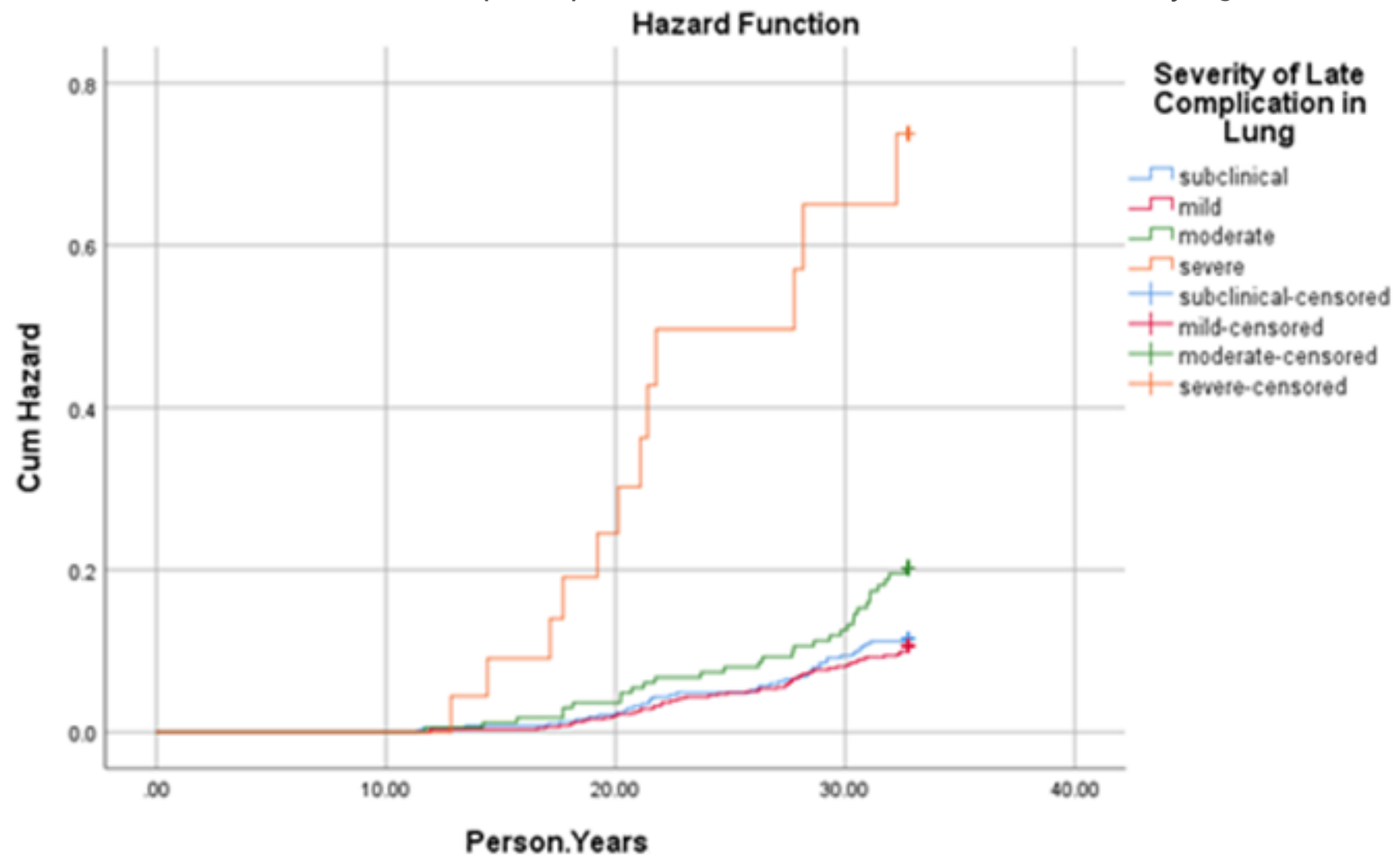

Figure 2

Cumulative death rates in the People Exposed to MG in Sardasht, Iran Stratified by Severity of Late Complication in Lung 